\title{
The first luminescence dating of Tibetan glacier basal sediment
}

\author{
Zhu Zhang, Shugui Hou, and Shuangwen Yi \\ School of Geographic and Oceanographic Sciences, Nanjing University, Nanjing, 210093, China
}

Correspondence: Shugui Hou (shugui@nju.edu.cn)

Received: 13 April 2017 - Discussion started: 10 May 2017

Revised: 30 November 2017 - Accepted: 8 December 2017 - Published: 16 January 2018

\begin{abstract}
Dating ice cores drilled in the high mountain glaciers is difficult because seasonal variations cannot be traced at depth due to rapid thinning of the ice layers. Here we provide the first luminescence dating of the basal sediment of the Chongce ice cap in the north-western Tibetan Plateau. Assuming the sediment is of similar (or older) age as the surrounding ice, the luminescence dating of $42 \pm 4 \mathrm{ka}$ provides an upper constraint for the age of the bottom ice at the drilling site. This result is more than 1 order of magnitude younger than the previously suggested age of the basal ice of the nearby Guliya ice cap $(\sim 40 \mathrm{~km}$ in distance).
\end{abstract}

\section{Introduction}

Ice cores from the high-elevation regions provide a wealth of information for past climatic and environmental conditions that extends beyond the instrumental period. A precise chronology is the essential first step for a reliable interpretation of the ice core records. The Tibetan Plateau (TP), sometimes called "the roof of the world", is the world's highest and largest plateau with an average elevation exceeding $4000 \mathrm{~m}$ a.s.l. (above sea level) and an area of 2.5 million $\mathrm{km}^{2}$. It has the largest number of glaciers outside the polar regions. In 1992, a $308.6 \mathrm{~m}$ ice core to bedrock was recovered from the Guliya ice cap on the north-western TP (Fig. 1). The top $266 \mathrm{~m}$ of the core was dated to a period spanning $110 \mathrm{ka}$, and the ice below $290 \mathrm{~m}$ was suggested to be more than $500 \mathrm{ka}$ old due to ${ }^{36} \mathrm{Cl}$-dead in the ice (Thompson et al., 1997). This makes it the second oldest continuous ice core, only younger than the Antarctic EPICA Dome C ice core. During the past two decades, the Guliya ice core record has been widely used as a benchmark for correlating regional climate variables in the westerlies of the central Asia and the northern Tibetan Plateau. However, Cheng et al. (2012) suggested a substan- tial revision of the Guliya chronology due to the enormous inconsistency between the $\delta^{18} \mathrm{O}$ records of the Guliya ice core and the Kesang stalagmite (Fig. 1 and Supplement).

Luminescence dating can be readily applied to most terrestrial sediments and can be used to date sediments on timescales from $10^{1}$ to $10^{5}$ years, encompassing the entire late Quaternary (Fuchs and Owen, 2008). Dating errors to within a few percent of the correct age can be achieved depending upon the nature of the sediment and the laboratory methods. During recent decades, the optically stimulated luminescence (OSL) method has been successfully used for dating glacial sediments on the TP and surrounding regions (e.g. Owen et al., 2003; Ou et al., 2014; Hu et al., 2015). Willerslev et al. (2007) provided the first luminescence measurements on the single grains of quartz and feldspar extracted from a sample cut out of an opaque part of the Greenland Dye 3 basal ice containing dispersed sandy and silty particles. To our knowledge, this is the only published luminescence dating of glacier basal ice so far. As pointed out by the authors, at the time when the Dye 3 ice core was drilled (1979-1981), no standard apparatus or procedures were used to avoid inadvertent exposure to light during the drilling and subsequent handling, inspection and storage of the ice cores. For this reason, the sample may be considered to be highly problematic for luminescence dating (Willerslev et al., 2007).

\section{The Chongce ice cores}

The Chongce ice cap is located in the western Kunlun Mountains on the north-western TP, with a snow line altitude about $5900 \mathrm{~m}$ a.s.l. It is $28.7 \mathrm{~km}$ in length, covering an area of $163.06 \mathrm{~km}^{2}$, with a volume of $38.16 \mathrm{~km}^{3}$. In 2012 , we drilled two ice cores to the bottom with lengths of 133.8 and $135.8 \mathrm{~m}$ and a shallow ice core with a length of $58.8 \mathrm{~m}$ at an altitude 
Table 1. Results of the fine quartz grains with their corresponding OSL ages.

\begin{tabular}{|c|c|c|c|c|c|c|c|c|c|c|}
\hline \multirow[t]{2}{*}{ Sample } & \multicolumn{2}{|c|}{$\mathrm{U}(\mathrm{ppm})$} & \multicolumn{2}{|c|}{ Th (ppm) } & \multicolumn{2}{|c|}{$\mathrm{K}(\%)$} & \multirow{2}{*}{$\begin{array}{c}D_{\mathrm{e}} \\
(\mathrm{Gy})\end{array}$} & \multirow{2}{*}{$\begin{array}{r}\text { Water content } \\
(\%)\end{array}$} & \multirow{2}{*}{$\begin{array}{l}\text { Dose rate } \\
\left(\mathrm{Gy} \mathrm{ka}^{-1}\right)\end{array}$} & \multirow{2}{*}{$\begin{array}{l}\text { Age } \\
(\mathrm{ka})\end{array}$} \\
\hline & Gamma & NAA & Gamma & NAA & Gamma & NAA & & & & \\
\hline CCICE* $^{*}$ & $3.66 \pm 0.15$ & $3.45 \pm 0.12$ & $11.21 \pm 0.42$ & $11.40 \pm 0.32$ & $3.52 \pm 0.10$ & $3.48 \pm 0.08$ & $178 \pm 9$ & $\begin{array}{r}0 \\
30 \pm 15\end{array}$ & $\begin{array}{l}5.81 \pm 0.46 \\
4.24 \pm 0.37\end{array}$ & $\begin{array}{l}31 \pm 3 \\
42 \pm 4\end{array}$ \\
\hline
\end{tabular}

* CCICE stands for Chongce ice.

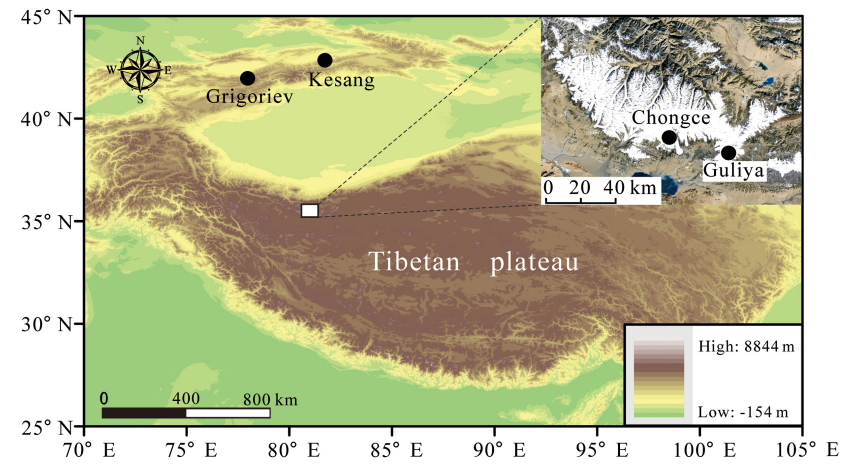

Figure 1. Study area map showing the locations of the Chongce and Guliya ice caps, the Kesang cave and the Grigoriev ice cap.

of $6010 \mathrm{~m}$ a.s.l. from the Chongce ice cap (Fig. S1 in the Supplement). The measured borehole temperature is about $-8.8^{\circ} \mathrm{C}$ at a depth of $130 \mathrm{~m}$. The very bottom of the core is a mixture of sediment and ice (see picture in Fig. S1). No special precautions were taken to avoid exposure to light during the drilling operation, so this mixture is not suitable for luminescence dating. Therefore, two more ice cores to the bottom were recovered with length of 216.6 and $208.6 \mathrm{~m}$ at an altitude of $6100 \mathrm{~m}$ a.s.l. $\left(35^{\circ} 14^{\prime} 57^{\prime \prime} \mathrm{N}, 81^{\circ} 5^{\prime} 28^{\prime \prime}\right.$ E. Fig. S1) in 2013. This time we managed to avoid exposure to light during the drilling and subsequent procedures. The drilling was performed at night. When it was close to the bottom, the cores, together with chips, were recovered in faint red light. Afterwards, the cores and chips were directly sacked into opaque plastic bags and immediately wrapped with aluminium foil and adhesive tape. The ice cores were kept frozen and transported to the cold room at Nanjing University for further processing.

\section{Sample preparation and measurements}

Sample preparation took place under the safe red light in the Luminescence Dating Laboratory of the Nanjing University. The total bottom sediment including ice is $1431.7 \mathrm{~g}$. We first took a small portion of the sediment $(13.4 \mathrm{~g})$ for measuring ice content, which is determined by weighting the mass before and after drying, resulting in $\sim 30 \%$ ice (water equivalent) content. Therefore, we assume that there might be $\sim 30 \%$ water at the bottom of the ice core drilling site during the warm period(s) in history. Moreover, because the water content may have varied over the entire burial period of the sample, we assigned a relative uncertainty of $50 \%$ to allow for possible fluctuations. Afterwards, this part of the sediment was dried in an oven $\left(<60^{\circ} \mathrm{C}\right)$. About $5 \mathrm{~g}$ of dried sediment was ground to a fine powder to determine $\mathrm{U}$, Th and $\mathrm{K}$ concentrations by neutron activation analysis (NAA) at the China Institute of Atomic Energy, Beijing. The results are given in Table 1. As the measured concentrations are normally low, the accuracy of the dose rates, calculated from the NAA results, may have been affected by the inhomogeneity of the deposits. Therefore, $\sim 100 \mathrm{~g}$ of sample was also measured for $>24 \mathrm{~h}$ using the high-resolution gamma spectrometry (Table S1 in the Supplement). The sample was ignited at $450^{\circ} \mathrm{C}$, cast in wax and stored for $>3$ weeks to assure equilibrium conditions for ${ }^{226} \mathrm{Ra}-{ }^{222} \mathrm{Rn}$ decay (Murray et al., 1987).

The rest of the sediment $(\sim 1300 \mathrm{~g})$ was put into a beaker and melted in the Luminescence Dating Laboratory at room temperature $\left(\sim 20^{\circ} \mathrm{C}\right)$. The meltwater was carefully extravasated. This process was repeated to leave as little water inside the beaker as possible. Then the sediment was filtered through the $200 \mu \mathrm{m}$ wet sieve. The filtered sediment was successively soaked in the $10 \%$ hydrochloric acid and $30 \%$ hydrogen peroxide to remove carbonate and organic matters. Afterwards, the residual was wet-sieved to separate the coarse grains $(90-150 \mu \mathrm{m})$ from the fine grains $(<40 \mu \mathrm{m})$.

The coarse grains were then separated by dense liquid $\left(2.58 \mathrm{~g} \mathrm{~cm}^{-3}\right)$, resulting in the coarse quartz grains at the bottom. After being purified with deionized water, the coarse $(90-150 \mu \mathrm{m})$ quartz grains were immersed in $40 \%$ hydrofluoric acid for $40 \mathrm{~min}$ to remove any remaining feldspar contamination, and in $10 \%$ hydrochloric acid for $40 \mathrm{~min}$ to remove residual fluoride. The purity of the quartz was determined using the OSL-infrared depletion ratio method (Duller, 2003). Even after being etched (40\% HF, $40 \mathrm{~min}$ ) twice, it was not possible to remove the feldspar completely. So, a post-IR measurement with a blue LED stimulation (Banerjee et al., 2001) was applied to the coarse-grain quartz measurements.

As for the fine grains $(<40 \mu \mathrm{m})$, a fraction $(4-11 \mu \mathrm{m})$ was further isolated according to Stokes' law. To extract pure fine quartz grains, the sample was first submerged in the $40 \%$ fluosilicic acid for 10 days and then in the $10 \%$ hydrochloric acid to remove any fluorides. The purity of treated fine grains was checked by the same method as that used with the coarse grain quartz (Duller, 2003). Samples with IRSL (in- 

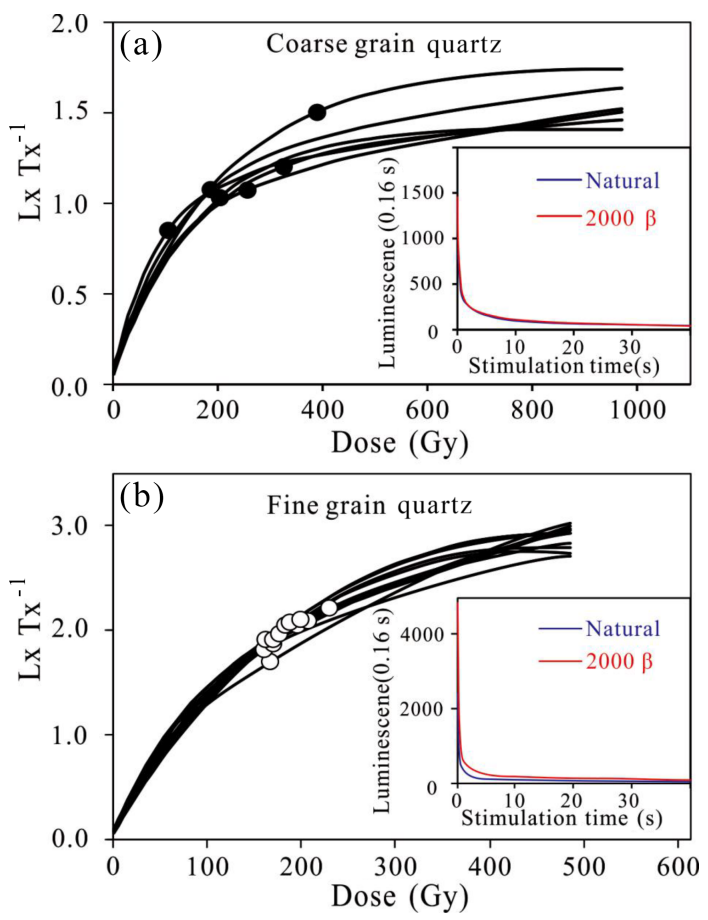

Figure 2. The OSL dose-response and decay curves of the coarseand fine-grain quartz aliquots. Inserts show decay curves of the natural and regenerated dose $(2000 \beta)$ of the sample.

frared stimulated luminescence) vs. blue OSL signal ratios over $10 \%$ of unity would be re-treated with fluosilicic acid until the ratio was within $10 \%$ of unity. The coarse quartz grains $(90-150 \mu \mathrm{m})$ were then mounted on stainless steel discs ( $\sim 2 \mathrm{~mm}$ in diameter) using the Silkospray silicone oil, and the fine quartz grains $(4-11 \mu \mathrm{m})$ were settled on discs using pure water and a pipette. Measurements were taken on a Ris $\varnothing$ TL/OSL reader (model DA-20C/D), fitted with blue LEDs $\left(470 \mathrm{~nm}, \sim 80 \mathrm{~mW} \mathrm{~cm}^{-2}\right)$, infrared LEDs $(870 \mathrm{~nm}$, $\sim 135 \mathrm{~mW} \mathrm{~cm}^{-2}$ ) and a ${ }^{90} \mathrm{Sr} /{ }^{90} \mathrm{Y}$ beta source (Bøtter-Jensen et al., 2010). The OSL signal from the quartz grains was detected by a 9235QA photomultiplier tube through a $7.5 \mathrm{~mm}$ Schott U-340 detection filter.

The quartz equivalent doses $\left(D_{\mathrm{e}}\right)$ were determined using the single aliquot regeneration (SAR) protocol (Murray and Wintle, 2000). A preheating temperature of $260^{\circ} \mathrm{C}$ with a cutheat of $220^{\circ} \mathrm{C}$ was selected for the $D_{\mathrm{e}}$ measurement with an elevated temperature $\left(280^{\circ} \mathrm{C}\right)$ blue light bleach at the end of each cycle. The early background subtraction (first $0.16 \mathrm{~s}$ minus background from 0.16 to $0.32 \mathrm{~s}$ interval) was used for signal integration and to minimize the influence of slow and medium components (Cunningham and Wallinga, 2010).

Individual $D_{\mathrm{e}}$ values were obtained using a singlesaturating exponential fitted in Analyst version 4.31.7 (Duller, 2015). The uncertainty of individual $D_{\mathrm{e}}$ values was calculated using counting statistics and an instrument uncertainty of $1.5 \%$.
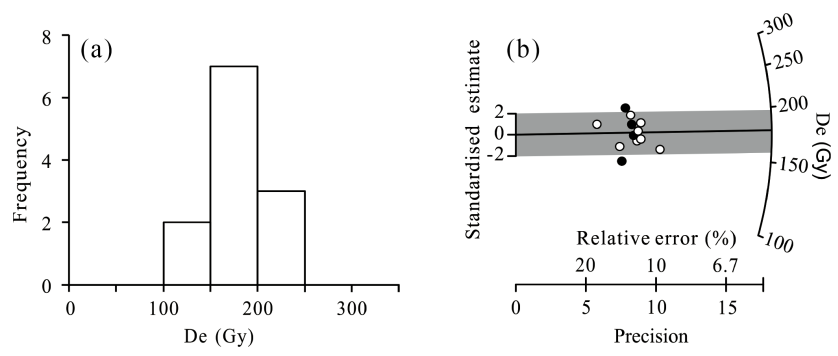

Figure 3. $D_{\mathrm{e}}$ distribution histogram (a) and radial plot (b) showing the distribution of $D_{\mathrm{e}}$ results for the fine grains. The shaded region represents $2 \sigma$ width of the distribution. The filled symbol represents the aliquots that were excluded in the final age calculation.

\section{Results and discussion}

The basic assumption of the OSL dating technique is that the mineral grains were fully bleached before being deposited. The possibility of complete bleaching of the grains decreases for materials from supraglacial debris, to englacial debris, to basal debris (Fuchs and Owen, 2008), suggesting that extreme care should be taken when applying the luminescence dating techniques to basal debris. The OSL dose-response and decay curves of the quartz aliquots are shown in Fig. 2. It is apparent that parts of the coarse grain $(90-150 \mu \mathrm{m})$ quartz aliquots approach the saturated level, but all the finegrain aliquots are similar and well below the saturated level. The decay curves of the fine grain $(4-11 \mu \mathrm{m})$ show that the OSL signal decreases very quickly and approaches the background level during the first seconds of stimulation. We further decomposed the natural OSL signal of the fine-grain aliquots into fast, medium and slow components (Fig. S2). The fast component accounts for around $87 \%$ of the natural signal, indicating that the signal is fast-component dominant. However, the OSL decay curves of the coarse grain aliquots display a relatively slow trend (Fig. 2). We also analysed the sediment sample with a scanning electron microscope. A typical coarse-grain quartz is shown in Fig. S3. Its angular texture and low degree of deformation suggest that this coarse grain quartz might have been scoured from bedrock, which mainly consists of Triassic high-K granitoids in the western Kunlun Mountains (Wang et al., 2013). In addition, the

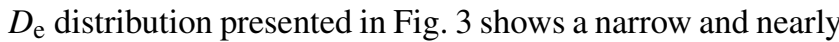
symmetric shape for the fine quartz grains, possibly indicating sufficient bleaching of the fine quartz grains. These results imply that the fine-grain quartz might be more appropriate for luminescence dating than the coarse grain quartz. The same conclusion was also reached in some previous studies on Himalayan glacial deposits (e.g. Hu et al., 2015). We therefore used the results of the fine grains, and the results from the coarse grain quartz were given in the Supplement (Table S3). Although the coarse grain ages are slightly older than the fine-grain ages (Table 1), they clearly fall within a similar range. 
We further evaluate the reliability of the quartz grain measurements by their recuperation and recycling ratios (Table S2). The recuperation values of all the fine-grain quartz aliquots are below $5 \%$ (Fig. S4). The recycling ratios range from 0.82 to 1.2 , with 9 of the 12 fine-grain quartz aliquots having recycling ratios within the acceptable range of 0.9 to 1.1 . Only the aliquots with recycling ratios within the acceptable range were used for further analysis. Among these, one additional aliquot was also excluded because its $D_{\mathrm{e}}$ value fell outside $2 \sigma$ of the distribution (Fig. 3). In the end, eight fine-grain quartz aliquots were used for OSL age calculation, resulting in an average equivalent dose $\left(D_{\mathrm{e}}\right)$ of $178 \pm 9$ Gy (Table 1).

Annual dose rate $(D)$ can be estimated from the $\mathrm{U}$, Th and $\mathrm{K}$ concentrations, water contents and cosmic ray contribution (Guérin et al., 2011). An alpha efficiency factor ( $a$-value) of $0.04 \pm 0.02$ for quartz (Rees-Jones, 1995) was used to calculate the alpha contribution to the total dose rate. The cosmic dose rate is negligible because the sediments are covered by thick ice and multiple dust layers, hence they are largely insulated from light and cosmic rays. There are potentially two additional sources of radiation that are not included in the dose rate calculation: (1) radiation from the bedrock, and (2) radiation from dust layers in the core. Willerslev et al. (2007) suggested that the dose rate contribution from the underlying bedrock at the Greenland Dye 3 ice core drilling site was negligible following calculations based on radiation transport modelling software (MCNP5). Because no literature values are available to calculate the dose rate contribution from the underlying bedrock at our drilling site, at the first stage it is assumed that its contribution to the dose rate was insignificant. As for radiation from dust layers in the core, we have not measured the dust concentrations of our Chongce ice cores, but a $18.7 \mathrm{~m}$ ice core drilled at the summit (6530 m a.s.l.) of the Chongce ice cap in 1992 gives a maximum dust mass concentration of $955 \mathrm{mg} \mathrm{kg}^{-1}$ ( $\mathrm{Li}$ et al., 2006). This provides a general impression of dust layers along the Chongce ice cores, which is $\sim 3$ orders of magnitude lower than the bottom sediment, suggesting an insignificant influence of radiation from dust layers in the core, given a similar radiation intensity of the dust layers in the core and the bottom sediment. Therefore, the increased dose rate would be expected if these additional sources of radiation were included, thus resulting in a younger age.

The converted $\mathrm{U}, \mathrm{Th}$ and $\mathrm{K}$ concentrations from the gamma measurements are close to the NAA results (Table 1), affirming the accuracy our element measurements. It is well recognized that water content is one of the major uncertainty factors of the Luminescence dose rate calculation because the real situation of sediments during geological history is not known. To approach this, two extreme situations for the sediment were presumed, one is zero water content which represents no ice (or water), and the other is the sediment full immersed by the water (saturation water content), i.e. $30 \pm 15 \%$ water content in our case. Under these two situ- ations, the maximum and minimum dose rates from water content were estimated. For these uncertainties, only an upper age constraint of $42 \pm 4 \mathrm{ka}$ is given in Table 1.

The dated fine-grain quartz aliquots are a mixture of Aeolian quartz and subglacially scoured quartz. Sharp and Gomez (1986) suggested that quartz particles should be "tools" producing comminution of softer minerals within subglacial environments while they themselves remain unaltered. Wright (1995) performed glacial grinding simulations by using a ring shear box designed to examine abrasion and size reduction of quartz grains under "grinding" conditions analogous to those experienced in a subglacial environment. The findings from experimental runs suggest that, although particle breakage and comminution do occur, little silt-sized material is actually produced. The amount of silt produced ranges from approximately $9 \%$ of the original sample in one experimental run to less than $1 \%$ for the other seven runs. The direct evidence is from Fig. S2, indicating that the fast component of the fine-grain aliquots accounts for around $87 \%$ of the natural OSL signal. So the signal is fast-component dominant. If for a high bedrock fraction, medium and slow components should be high due to no or less bleaching of the bedrock. So the fine quartz grains used for the dating are mostly of Aeolian origin, implying that the luminescence dating would represent the time for the ice to move from the surface to the bed.

Our new data do not imply that there was an ice-free region in the Chongce region $42 \pm 4 \mathrm{ka}$ ago, but that an icefree condition has existed below the elevation of the bottom at the drilling site during one or more warm periods since this upper age constraint (e.g. the Bølling-Allerød period, Holocene Climate Optimum). Takeuchi et al. (2014) reported radiocarbon dating of organic soil from the bottom of an $86.87 \mathrm{~m}$ ice core drilled at the top of the Grigoriev ice cap $\left(41^{\circ} 58^{\prime} 33^{\prime \prime} \mathrm{N}, 77^{\circ} 54^{\prime} 48^{\prime \prime} \mathrm{E}\right)$ in the Tien Shan Mountains, showing that the age of the soil is $12656-12434$ cal yr BP (years before present). Therefore, Takeuchi et al. (2014) suggested that the Grigoriev ice cap did not exist in the BøllingAllerød period, which gives support to our results.

Given the surface elevation of the Chongce drilling site of $6100 \mathrm{~m}$ a.s.l. and the ice core length of $216.6 \mathrm{~m}$, the elevation at the bottom of the Chongce drilling site is $5883.4 \mathrm{~m}$ a.s.l. As to the Guliya ice core drilling site, its surface elevation of $6200 \mathrm{~m}$ a.s.l. and its length of $308.6 \mathrm{~m}$ result in an elevation at the bottom of $5891.4 \mathrm{~m}$ a.s.l., suggesting that the age of the bottom ice at the Chongce and the Guliya drilling sites might be comparable. Thus our new data cannot support the previously suggested age of more than $500 \mathrm{ka}$ of the Guliya bottom ice (Thompson et al., 1997). 


\section{Conclusions}

An upper age constraint ( $42 \pm 4 \mathrm{ka})$ of the basal sediment sample from the Chongce ice cap in the western Kunlun Mountains on the north-western TP is estimated, which is more than 1 order of magnitude younger than the previously suggested age of bottom ice in the western Kunlun Mountains. The major limitation of the current work is the very small number of absolute ages and simple assumptions, and there exists much uncertainty, e.g. in the determination of the dose rate, additional radiation sources from bedrock and dust layers in the core and specific processes underneath the glacier. For these reasons, we suggest only an upper constraint for the age of the sediment. Future work should include collecting more glacier basal sediment samples for the luminescence dating, better understanding the unique processes for preserving the luminescence signal in the glacier basal sediment, and effect of ice on the dose rate. However, the current work provides potential implications for exploring the age of mountainous glacier bottom ice and is an important step towards a better understanding the Tibetan ice cores and a more accurate interpretation of their records.

Data availability. All the data used in this paper are given in the Supplement.

\section{The Supplement related to this article is available online at https://doi.org/10.5194/tc-12-163-2018-supplement.}

Author contributions. SH designed this work and drilled the ice cores. ZZ and SY took the measurements. SH wrote the paper. All authors contributed to a discussion of the results.

Competing interests. The authors declare that they have no conflict of interest.

Acknowledgements. Thanks are due to many scientists, technicians, graduate students and porters for their hard work in the field, to Hongxi Pang and Wangbin Zhang for help in sampling, and to Zhongpin Lai, Lupeng Yu and Yuanfeng Cai for discussion. This work was supported by the National Natural Science Foundation of China (41330526). We are grateful to three anonymous reviewers, Joel Gombiner and the editor Julia Boike for their constructive comments, which helped to improve the paper.

Edited by: Julia Boike

Reviewed by: three anonymous referees

\section{References}

Banerjee, D., Murray, A. S., Bøtter-Jensen, L., and Lang, A.: Equivalent dose estimation using a single aliquot of polymineral fine grains, Radiat. Meas., 33, 73-94, 2001.

Bøtter-Jensen, L., Thomsen, K. J., and Jain, M.: Review of optically stimulated luminescence (OSL) instrumental developments for retrospective dosimetry, Radiat. Meas., 45, 253-257, 2010.

Cheng, H., Zhang, P. Z., Spötl, C., Edwards, R. L., Cai, Y. J., Zhang, D. Z., Sang, W. C., Tan, M., and An, Z. S.: The climatic cyclicity in semiarid-arid central Asia over the past 500,000 years, Geophys. Res. Lett., 39, L01705, https://doi.org/10.1029/2011GL050202, 2012.

Cunningham, A. C. and Wallinga, J.: Selection of integration time intervals for quartz OSL decay curves, Quatern. Geochron., 5, 657-666, 2010.

Duller, G. A. T.: Distinguishing quartz and feldspar in single grain luminescence measurements, Radiat. Meas., 37, 161-165, 2003.

Duller, G. A. T.: The Analyst software package for luminescence data: overview and recent improvements, Anc. TL, 33, 35-42, 2015.

Fuchs, M. and Owen, L. A.: Luminescence dating of glacial and associated sediments: review, recommendations and future directions, Boreas, 37, 636-659, https://doi.org/10.1111/j.15023885.2008.00052.x, 2008.

Guérin, G., Mercier, N., and Adamiec, G.: Dose rate conversion factors: update, Anc. TL, 29, 5-8, 2011.

Hu, G., Yi, C. L., Zhang, J. F., Liu, J. H., and Jiang, T.: Luminescence dating of glacial deposits near the eastern Himalayan syntaxis using different grain-size fractions, Quaternary Sci. Rev., 124, 124-144, https://doi.org/10.1016/j.quascirev.2015.07.018, 2015.

Li, Y., Yang, Y., Han, J., Xie, Z., Nakawo, M., and Goto-Azuma, K.: Persistent decrease of dust burden for about 100 years over middle-upper Troposphere of the southern Taklimakan Desert, China, J. Glaciol. Geocryol., 28, 873-878, 2006. (in Chinese with English abstract).

Murray, A. S. and Wintle, A. G.: Luminescence dating of quartz using an improved single-aliquot regenerative-dose protocol, Radiat. Meas., 32, 57-73, https://doi.org/10.1016/S13504487(99)00253-X, 2000.

Murray, A. S., Marten, R., Johnston, A., and Martin, P.: Analysis for naturally occurring radionuclides at environmental concentrations by gamma spectrometry, J. Rad. Nuc. Chem., 115, 263288, 1987.

Ou, X. J., Lai, Z. P., Zhou, S. Z., and Zeng, L. H.: Timing of glacier fluctuations and trigger mechanisms in eastern Qinghai-Tibetan Plateau during the late Quaternary, Quatern. Res., 81, 464-475, https://doi.org/10.1016/j.yqres.2013.09.007, 2014.

Owen, L. A., Spencer, J. Q., Ma, H., Barnard, P. L., Derbyshire, E., Finkel, R. C., Caffee, M. W., and Zeng, Y.N.: Timing of late quaternary glaciation along the southwestern slopes of the Qilian Shan, Tibet, Boreas, 32, 281-291, https://doi.org/10.1111/j.1502-3885.2003.tb01083.x, 2003.

Rees-Jones, J.: Optical dating of young sediments using fine-grain quartz, Anc. TL, 13, 9-14, 1995.

Sharp, M. and Gomez, B.: Processes of debris comminution in the glacial environment and implications for quartz sand-grain micromorphology, Sediment. Geol., 46, 33-47, 1986. 
Takeuchi, N., Fujita, K., Aizen, V. B., Narama, C., Yokoyama, Y., Okamoto, S., Naoki, K., and Kubota, J.: The disappearance of glaciers in the Tien Shan Mountains in central Asia at the end of Pleistocene, Quaternary Sci. Rev., 103, 26-33, https://doi.org/10.1016/j.quascirev.2014.09.006, 2014.

Thompson, L. G., Yao, T., Davis, M. E., Henderson, K. A., MosleyThompson, E., Lin, P.-N., Beer, J., Synal, H.-A., Cole-Dai, J., and Bolzan, J. F.: Tropical climate instability: the last glacial cycle from a Qinghai-Tibetan ice core, Science, 276, 1821-1825, https://doi.org/10.1126/science.276.5320.1821, 1997.

Wang, L., Pan, G., Ding, J., and Yao, D.: Geological mapping of Qinghai-Tibet Plateau and its adjacent area (1:1500 000), Geological Publishing House, Beijing, 2013.
Willerslev, E., Cappellini, E., Boomsma, W., Nielsen, R., Hebsgaard, M. B., Brand, T. B., Hofreiter, M., Bunce, M., Poinar, H. N., Dahl-Jensen, D., Johnsen, S., Steffensen, J. P., Bennike, O., Schwenninger, J.-L., Nathan, R., Armitage, S., de Hoog, C.-J., Alfimov, V., Christl, M., Beer, J., Muscheler, R., Barker, J., Sharp, M., Penkman, K. E. H., Haile, J., Taberlet, P., Gilbert, M. T. P., Casoli, A., Campani, E., and Collins, M. J.: Ancient biomolecules from deep ice cores reveal a forested southern Greenland, Science, 317, 111-114, https://doi.org/10.1126/science.1141758, 2007.

Wright, J. S.: Glacial comminution of quartz sand grains and the production of loessic silt: a simulation study, Quaternary Sci. Rev., 14, 669-680, 1995. 